\title{
Prostate cancer and body size at different ages: an Italian multicentre case-control study
}

\author{
L Dal Maso*, , A Zucchetto', C La Vecchia ${ }^{2,3}$, M Montella ${ }^{4}$, E Conti ${ }^{5,9}$, V Canzonieri', R Talamini', A Tavani ${ }^{2}$, \\ E Negri ${ }^{2}$, A Garbeglio $^{7}$ and S Franceschi ${ }^{8}$ \\ 'Servizio di Epidemiologia e Biostatistica, Centro di Riferimento Oncologico, Via Pedemontana Occ.le 12, 3308I Aviano (PN), Italy; ${ }^{2}$ Istituto di Ricerche \\ Farmacologiche 'Mario Negri', Via Eritrea 62, 20157 Milano, Italy; ${ }^{3}$ Istituto di Statistica Medica e Biometria, Università degli Studi di Milano, Via Venezian \\ I, 20133 Milano, Italy; ' Servizio di Epidemiologia, Istituto Tumori 'Fondazione Pascale', Cappella dei Cangiani, 80 I 3 I Napoli, Italy; ${ }^{5}$ Senvizio Integrato di \\ Epidemiologia e Sistemi Informativi (SINTESI), Via Chianesi 53, 00128 Roma, Italy; ${ }^{6}$ Divisione di Anatomia Patologica, Centro di Riferimento Oncologico, \\ Via Pedemontana Occ.le 12, 33081 Aviano (PN), Italy; ${ }^{7}$ Unità Operativa di Urologia, Azienda Ospedaliera di Pordenone, Via Montereale 24, 33170 \\ Pordenone, Italy; ${ }^{8}$ International Agency for Research on Cancer, 150 Cours A. Thomas, 69008 Lyon, France
}

We investigated the influence of anthropometric measures at diagnosis and at different ages on prostate cancer risk using an Italian multicentre case-control study conducted between 199| and 2002 of 1294 histologically confirmed cases and I45| controls admitted to the same network of hospitals for acute non-neoplastic conditions. Height, weight, body mass index (BMI), waist-to-hip ratio, lean body mass I year before diagnosis/interview were not significantly associated with risk. However, a positive association with high $\mathrm{BMI}$ at age 30 years was found (odds ratio $=1.2$ for $\mathrm{BMI} \geqslant 24.7$ vs $<22.7$ ) and: for less differentiated prostate cancer, with BMI I year before diagnosis/interview. This study supports possible relationships between high body mass in young adulthood, and a tendency to high weight throughout adult life, and the risk of prostate cancer.

British Journal of Cancer (2004) 90, 2176-2180. doi:10.1038/sj.bjc.6601859 www.bjcancer.com

Published online 4 May 2004

(c) 2004 Cancer Research UK

Keywords: case-control study; prostate cancer; body mass index

Age, race and family history are the only well-established risk factors for prostate cancer, one of the commonest types of cancer in developed countries (Hsing and Devesa, 2001; Grönberg, 2003).

Several studies have reported weak or no association (IARC, 2002) with adult weight, body mass index (BMI) and lean body mass (LBM) (Habel et al, 2000; Nomura, 2001; Engeland et al, 2003; Giles et al, 2003). Only a large cohort study (Giovannucci et al, 2003b) reported an inverse association with BMI, with a relative risk of 0.5 in younger men. A direct association with body mass measures was found in certain studies focusing on fatal (Andersson et al, 1997; Rodriguez et al, 2001) or advanced prostate cancer (Putnam et al, 2000; Giles et al, 2003), suggesting that high BMI may facilitate the progression of prostatic neoplasms (Nomura, 2001).

A moderate positive association between height and prostate cancer was reported in several cohort studies of incidence (Andersson et al, 1997; Giovannucci et al, 1997; Engeland et al, 2003) or mortality (Andersson et al, 1997; Freeman et al, 2001; Rodriguez et al, 2001). Conversely, case-control studies have mainly reported no increase of prostate cancer risk in taller men (Whittemore et al, 1995; Villeneuve et al, 1999; Gunnell et al, 2001; Giles et al, 2003).

\footnotetext{
*Correspondence: L Dal Maso; E-mail: epidemiology@cro.it

${ }^{9}$ Deceased.

Received 20 January 2004; revised 17 March 2004; accepted 17 March

2004; published online 4 May 2004
}

Waist-to-hip ratio (WHR), an index of central adiposity, was not consistently associated with prostate cancer risk (Whittemore et al, 1995; Giles et al, 2003; Giovannucci et al, 2003b).

Our large Italian case-control study, including extensive information on body size indices at various ages and major potential confounding factors, has allowed further investigation of the role of body size measures in prostate carcinogenesis.

\section{MATERIALS AND METHODS}

Cases included were 1294 men (median age 66, range $46-74$ years) with incident, histologically confirmed prostate cancer admitted to the major teaching and general hospitals in the provinces of Pordenone and Gorizia and the greater Milan area in northern Italy, the province of Latina in central Italy and the urban area of Naples in southern Italy.

Controls were 1451 men (median age 63, range 46-74 years), admitted for a wide spectrum of acute conditions unrelated to known or potential risk factors for prostate cancer to hospitals sharing the same catchment's areas of those where cases were referred to. Among controls, $32 \%$ had nontraumatic orthopaedic disorders, $21 \%$ traumas, $17 \%$ surgical conditions and $29 \%$ miscellaneous other illnesses, such as eye, ear and dental disorders. Less than $5 \%$ of both cases and controls contacted refused the interview, and the participation did not vary across hospitals and geographic areas.

All interviews were conducted in a hospital setting using a structured questionnaire, which included information on age, 
education and other socioeconomic factors, physical activity, smoking habit, alcohol intake, an itemised food frequency section, a problem-oriented medical history and history of cancer in firstdegree relatives. Body size indexes at different ages were collected in a detailed section of the questionnaire. Study subjects were asked to report their height and habitual weight 1 year prior to cancer diagnosis or interview (in controls). Information on perceived body size at 12 years of age (i.e.: thinner than, same as, heavier than peers), weight at ages 30 and 50, highest and lowest weight in adult life were also collected. The interviewers measured the circumference of the waist $(2 \mathrm{~cm}$ above the umbilicus) and hips (maximal protrusion), and WHR was computed. In $25 \%$ of prostate cancer cases and $24 \%$ of control subjects, waist or hip could not be measured for technical reasons. BMI was computed as weight/height ${ }^{2}\left(\mathrm{~kg} \mathrm{~m}^{-2}\right)$ and, since it was suggested that BMI does not differentiate lean and fat masses (Nomura, 2001), LBM was also computed using the appropriate algorithm $((2.447-0.09516 \times$ age $+0.1074 \times$ height $+0.3362 \times$ weight $) / 0.732)$ (Willett, 1999).

Approximate tertiles or quartiles by various body size indexes were computed on the basis of the combined distribution of cases and controls. Odds ratios (OR) of prostate cancer and the corresponding $95 \%$ confidence intervals (CI), for various body measures, were calculated using unconditional multiple logistic regression, fitted by the method of maximum likelihood (Breslow and Day, 1980). The effect of several potential confounding factors was considered, including study centre, age in 5-year groups, education, occupational physical activity and family history of prostate cancer in first-degree relatives. Additional adjustment for energy intake and smoking habits did not materially modify our results. Tests for linear trends were assessed by means of the Wald $\chi^{2}$ on the variables considered as categorical. Selected analyses were repeated separately according to the TNM pathological stage (Sobin and Wittekind, 1997) and the degree of histological differentiation (Gleason score; Gleason and Mellinger, 1974).

\section{RESULTS}

Table 1 gives the distribution of cases and controls according to age and selected covariates. Prostate cancer cases were significantly more educated than controls; they had a lower occupational physical activity, and reported a family history of prostate cancer (7\%) more frequently than controls $(2 \%)$. Pathological stage was available in $42 \%$ of prostate cancer cases and Gleason score in $71 \%$ (Table 1).

Table 2 shows the distribution of prostate cancer and controls and the corresponding ORs, according to various body size measures 1 year before diagnosis/interview. Comparing the highest with the lowest quartiles, the ORs were close to unity for height, weight, WHR and LBM. The three highest quartiles of BMI were associated with slightly increased ORs, compared to the lowest quartile, but the risk trend was not significant $(P=0.23)$.

No association with prostate cancer risk was found with perceived body size compared to peers at 12 years of age (Table 3). However, a weak direct association was found with $\mathrm{BMI}$ at age $30(\mathrm{OR}=1.2 ; 95 \% \mathrm{CI}: 1.0-1.5$, for $\mathrm{BMI} \geqslant 24.7$ vs $<22.7)$, and with the lowest $\mathrm{BMI}$ in adult life $(\mathrm{OR}=1.3,95 \% \mathrm{CI}$ : $1.1-1.6$, for $\mathrm{BMI} \geqslant 23.1$ vs $<21.2$ ). Subjects with lifetime BMI increase equal to 5.7 units or greater, compared to the lowest tertile (less than 3.2): had an OR of developing prostate cancer of 0.8 (95\% CI: 0.7-1.0) (Table 3).

The pattern of association of prostate cancer with BMI at diagnosis/interview or at age 30 was similar below and above 65 years of age at diagnosis. The association between LBM at various ages and prostate cancer risk was similar to that for BMI; no association emerged with BMI at age 50 and maximal lifetime BMI (data not shown in tables).
Table I Distribution of I 294 cases of prostate cancer and I45I controls according to age and selected covariates. Italy, |99|-2002

\begin{tabular}{|c|c|c|}
\hline & Cases no. (\%) & Controls no. (\%) \\
\hline \multicolumn{3}{|l|}{ Age } \\
\hline $45-59$ & $219(16.9)$ & $431(29.7)$ \\
\hline $60-64$ & $310(24.0)$ & $359(24.7)$ \\
\hline $65-69$ & $419(32.4)$ & $364(25.1)$ \\
\hline $70-74$ & $346(26.7)$ & $297(20.5)$ \\
\hline \multicolumn{3}{|l|}{ Education (years) ${ }^{\mathrm{a}}$} \\
\hline$<7$ & $636(49.6)$ & $844(58.5)$ \\
\hline $7-11$ & $384(29.9)$ & $407(28.2)$ \\
\hline$\geqslant 12$ & $263(20.5)$ & $192(13.3)$ \\
\hline \multicolumn{3}{|c|}{ Occupational physical activity at age $30^{\mathrm{a}}$} \\
\hline Very active & $518(40.2)$ & $684(47.1)$ \\
\hline Moderately active & $335(26.0)$ & $393(27.1)$ \\
\hline Inactive & $437(33.9)$ & $374(25.8)$ \\
\hline \multicolumn{3}{|c|}{ Family history of prostate cancer in first-degree relatives } \\
\hline No & $1204(93.0)$ & | $423(98.1)$ \\
\hline Yes & $90(7.0)$ & $28(1.9)$ \\
\hline \multicolumn{3}{|l|}{ Pathological stage (TNM) } \\
\hline $1-\|$ & $321(24.8)$ & \\
\hline III-IV & $231(17.9)$ & \\
\hline Unknown & $742(57.3)$ & \\
\hline \multicolumn{3}{|l|}{ Histological grade (Gleason score) } \\
\hline 2-6 (more differentiated) & $538(41.6)$ & \\
\hline $7-10$ & $384(29.7)$ & \\
\hline Unknown & $372(28.8)$ & \\
\hline
\end{tabular}

The sum does not add up to the total because of some missing values.

Table 4 shows the association of prostate cancer and BMI at diagnosis/interview and at age 30 in different strata of pathological stage and Gleason score. The direct association with BMI at diagnosis/interview was slightly stronger among men with stage III-IV and less differentiated tumours. The OR for BMI $\geqslant 28.4 v s$ $<24.2$ among cases with Gleason score $7-10$ was 1.6 (95\% CI: $1.1-2.3)$. The association with BMI at age 30 was consistent in different strata of pathological stage and Gleason score (Table 4).

\section{DISCUSSION}

The main findings of our study are associations between prostate cancer and BMI at age 30 years and with a relatively elevated BMI throughout adult life, as implied by reporting a relatively high lowest BMI or a low BMI increase life long (Table 3). No trend in risk according to BMI at diagnosis/interview emerged. Weight, WHR and LBM at ages close to diagnosis or during adolescence were also unrelated to prostate cancer risk.

Some studies (Andersson et al, 1997; Giovannucci et al, 1997) have shown a direct relationship between height and prostate cancer risk, suggesting a possible role of nutritional status or levels of circulating growth factors during puberty. Height, however, was unrelated to prostate cancer risk in our study and in several other studies (Hsieh et al, 1999; Hsing et al, 2000; Rodriguez et al, 2001).

With few exceptions, recent BMI was also found to be unrelated to prostate cancer risk in case-control studies (Kolonel, 1996; Giles et al, 2003). Prospective studies are more supportive of a positive association, particularly, those that included prostate cancer mortality as end point (Putnam et al, 2000; Rodriguez et al, 2001). Obesity and its hormonal and metabolic correlates may increase prostate cancer progression and decrease survival. In our study, cases with less differentiated and, hence, prognostically 
worse prostate cancer (Gleason and Mellinger, 1974) showed an association with BMI at diagnosis, although the findings by Gleason score were not significantly heterogeneous. Moreover, a

Table 2 Distribution of 1294 cases of prostate cancer and |45| controls, OR a and corresponding $95 \% \mathrm{Cl}$, according to body-size measures at diagnosis/interview. Italy, 1991-2002 ${ }^{\text {b }}$

\begin{tabular}{|c|c|c|c|c|}
\hline & Cases & Controls & OR & $(95 \% \mathrm{Cl})$ \\
\hline \multicolumn{5}{|l|}{ Height $(\mathrm{cm})$} \\
\hline$<169$ & 353 & 420 & 1 & \\
\hline $169-172$ & 353 & 372 & 1.11 & $(0.89-1.37)$ \\
\hline $173-176$ & 278 & 323 & 0.96 & $(0.76-1.20)$ \\
\hline$\geqslant 177$ & 307 & 335 & 0.98 & $(0.78-1.23)$ \\
\hline$\chi^{2}$ trend & & & 0.30 & $P=0.59$ \\
\hline \multicolumn{5}{|l|}{ Weight (kg) } \\
\hline$<71$ & 303 & 370 & 1 & \\
\hline $71-78$ & 359 & 374 & 1.13 & $(0.91-1.40)$ \\
\hline $79-85$ & 343 & 356 & 1.16 & $(0.93-1.45)$ \\
\hline$\geqslant 86$ & 287 & 348 & 1.02 & $(0.81-1.28)$ \\
\hline$\chi^{2}$ trend & & & 0.05 & $P=0.82$ \\
\hline \multicolumn{5}{|c|}{ Body mass index $\left(\mathrm{kg} \mathrm{m}^{-2}\right)$} \\
\hline$<24.22$ & 301 & 368 & I & \\
\hline 24.22 to $<26.18$ & 346 & 356 & 1.18 & $(0.95-1.47)$ \\
\hline 26.18 to $<28.41$ & 324 & 365 & 1.12 & $(0.89-1.40)$ \\
\hline$\geqslant 28.41$ & 319 & 358 & 1.18 & $(0.94-1.47)$ \\
\hline$\chi^{2}$ trend & & & 1.42 & $P=0.23$ \\
\hline \multicolumn{5}{|l|}{ Waist-to-hip ratio } \\
\hline$<0.93$ & 229 & 240 & 1 & \\
\hline 0.93 to $<0.96$ & 209 & 293 & 0.74 & $(0.57-0.97)$ \\
\hline 0.96 to $<0.99$ & 270 & 296 & 0.93 & $(0.72-1.19)$ \\
\hline$\geqslant 0.99$ & 258 & 279 & 0.95 & $(0.73-1.24)$ \\
\hline$\chi^{2}$ trend & & & 0.01 & $P=0.93$ \\
\hline \multicolumn{5}{|l|}{ Lean body mass } \\
\hline$<52.36$ & 315 & 368 & 1 & \\
\hline 52.36 to $<56.19$ & 341 & 346 & 1.17 & $(0.94-1.46)$ \\
\hline 56.19 to $<59.88$ & 321 & 362 & 1.10 & $(0.88-1.38)$ \\
\hline$\geqslant 59.88$ & 313 & 371 & 1.09 & $(0.87-1.37)$ \\
\hline$\chi^{2}$ trend & & & 0.28 & $P=0.60$ \\
\hline
\end{tabular}

${ }^{a}$ Estimates from multiple logistic regression equations, including terms for age (quinquennia), study centre, education, physical activity and family history of prostate cancer. ${ }^{\text {b}}$ The sum may not add up to the total because of some missing values. positive modest association between measures of adiposity and the risk of aggressive disease emerged also in a prospective cohort study from Australia (MacInnis et al, 2003).

The relevant exposure period for the association between body size and prostate cancer, if it exists, is also unclear. Being overweight in adolescence (i.e. perceived body size compared to one's peers at age 12) was unrelated to prostate cancer risk in our as well as in a few previous studies (Giovannucci et al, 1997; Giles et al, 2003). We found, however, a direct association with weight gain early in adult life and, notably, with BMI at age 30 years. It is possible that, conversely to breast cancer in women, which is

Table 3 Distribution of 1294 cases of prostate cancer and |45| controls, $\mathrm{OR}^{\mathrm{a}}$ and corresponding $95 \% \mathrm{Cl}$, according to body-size measures during lifetime. Italy, 1991-2002

\begin{tabular}{|c|c|c|c|c|}
\hline & Cases & Controls & OR & $(95 \% \mathrm{Cl})$ \\
\hline \multicolumn{5}{|c|}{ Perceived body size at age 12} \\
\hline Thinner & 521 & 575 & I & \\
\hline Same & 492 & 549 & 1.00 & $(0.84-1.20)$ \\
\hline Heavier & 265 & 315 & 0.95 & $(0.77-1.17)$ \\
\hline$\chi^{2}$ trend & & & 0.18 & $P=0.67$ \\
\hline \multicolumn{5}{|c|}{$\mathrm{BMl}$ at age $30\left(\mathrm{~kg} \mathrm{~m}^{-2}\right)$} \\
\hline$<22.65$ & 406 & 492 & I & \\
\hline 22.65 to $<24.69$ & 437 & 430 & 1.33 & $(1.09-1.62)$ \\
\hline$\geqslant 24.69$ & 414 & 459 & 1.22 & $(1.01-1.48)$ \\
\hline$\chi^{2}$ trend & & & 4.04 & $P=0.04$ \\
\hline \multicolumn{5}{|l|}{ Lowest BMl $\left(\mathrm{kg} \mathrm{m}^{-2}\right)$} \\
\hline$<21.22$ & 420 & 490 & । & \\
\hline 21.22 to $<23.14$ & 402 & 468 & 1.08 & $(0.89-1.31)$ \\
\hline$\geqslant 23.14$ & 447 & 443 & 1.32 & $(1.08-1.60)$ \\
\hline$\chi^{2}$ trend & & & 7.70 & $P<0.01$ \\
\hline \multicolumn{5}{|c|}{ Increase of BMI from lowest $\left(\mathrm{kg} \mathrm{m}^{-2}\right)^{\mathrm{c}}$} \\
\hline$<3.15$ & 412 & 412 & 1 & \\
\hline 3.15 to $<5.67$ & 399 & 402 & 0.98 & $(0.80-1.20)$ \\
\hline$\geqslant 5.67$ & 359 & 442 & 0.82 & $(0.67-1.01)$ \\
\hline$\chi^{2}$ trend & & & 3.54 & $P=0.06$ \\
\hline
\end{tabular}

${ }^{a}$ Estimates from multiple logistic regression equations, including terms for age (quinquennia), study centre, education, physical activity and family history of prostate

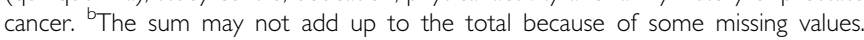
'Subject with lowest BMI reported less than 5 years before diagnosis/interview were excluded.

Table 4 Distribution of prostate cancer cases and controls, $\mathrm{OR}^{\mathrm{a}}$ and corresponding $95 \% \mathrm{Cl}$ according to stage, grade, and $\mathrm{BMI}\left(\mathrm{kg} \mathrm{m}^{-2}\right)$ at diagnosis/ interview and at age 30. Italy, 1991-2002

\begin{tabular}{|c|c|c|c|c|c|c|c|c|c|}
\hline & \multirow{2}{*}{ Controls } & \multicolumn{4}{|c|}{ Stage (TNM) } & \multicolumn{4}{|c|}{ Grade (Gleason score) } \\
\hline & & \multicolumn{2}{|r|}{ I-II } & \multicolumn{2}{|r|}{ III-IV } & \multicolumn{2}{|r|}{$2-6$} & \multicolumn{2}{|r|}{$7-10$} \\
\hline \multicolumn{10}{|c|}{ BMI at diagnosis/interview } \\
\hline$<24.22$ & 368 & 79 & 1 & 45 & I & 126 & 1 & 69 & 1 \\
\hline 24.22 to $<26.18$ & 356 & 88 & $1.12(0.78-1.60)$ & 67 & $1.47(0.96-2.25)$ & 153 & $1.27(0.95-1.69)$ & 102 & $1.49(1.05-2.12)$ \\
\hline$\chi^{2}$ trend & & 0.07 & $P=0.79$ & 1.38 & $P=0.24$ & 0.06 & $P=0.81$ & 6.38 & $P=0.01$ \\
\hline \multicolumn{10}{|l|}{ BMl at age 30} \\
\hline$<22.65$ & 492 & 102 & 1 & 59 & 1 & 157 & 1 & 112 & 1 \\
\hline 22.65 to $<24.69$ & 430 & 109 & $1.21(0.87-1.67)$ & 88 & $1.87(1.29-2.72)$ & 190 & $1.50(1.16-1.95)$ & 139 & $1.60(1.19-2.15)$ \\
\hline$\geqslant 24.69$ & 459 & 107 & $1.20(0.87-1.65)$ & 84 & $1.62(1.11-2.35)$ & 180 & $1.36(1.04-1.76)$ & 129 & $1.39(1.03-1.87)$ \\
\hline
\end{tabular}

${ }^{a}$ Estimates from multiple logistic regression equations, including terms for age (quinquennia), study centre, education, physical activity, and family history of prostate cancer. 
greatly affected by events in puberty and young adulthood, the most relevant exposure period for prostate cancer may be later, perhaps in the fourth decade of life. This may be indirectly supported by the special age distribution of prostate cancer incidence that shows an exponential rise beginning at approximately age 50-55 (i.e. later than any other cancer site, including hormone dependent tumours in women) (Signorello and Adami, 2002). The association between weight or BMI and prostate cancer must be, however, weak or, possibly, weakened by some illunderstood heterogeneity in the disease.

Effects of long-term, even mild, overweight on prostate cancer risk could be mediated by several biological mechanisms, implicating sex hormones (androgens and oestrogen) (Nomura, 2001), leptin, and insulin-like growth factor (IGF)-I (Chan et al, 1998; Calle, 2000; Hsing and Devesa, 2001; Pollak, 2001). However, the relationship between nutritional factors, IGF system, serum and tissue hormones, anthropometric measures, and prostate carcinogenesis is complex and ill understood (Calle, 2000; Pollak, 2001; Moyad, 2002; Giovannucci et al, 2003a).

In our study, problems of reliability in anthropometric measures cannot be excluded; however, there is no evidence that weight was differentially reported by cases and controls (Casey et al, 1991). Indeed, there was no reason for recall bias in current weight and height, in our study, as cases and controls were interviewed in similar hospital settings and the general population was unaware of the possible relationship (D'Avanzo et al, 1997). Past body measures are generally well correlated with correspon-

\section{REFERENCES}

Andersson SO, Wolk A, Bergstrom R, Adami H-O, Enholm G, Englund A, Nyrén O (1997) Body size and prostate cancer: a 20 year follow-up among 135,006 Swedish construction workers. J Natl Cancer Inst 89: $385-389$

Breslow NE, Day NE (1980) Statistical Methods in Cancer Research. Vol 1. The Analysis of Case-Control Studies. Lyon: IARC IARC Sci Publ 32

Calle EE (2000) Invited commentary: Do anthropometric measures predict risk of prostate cancer? Am J Epidemiol 151: 550-553

Casey VA, Dwyer JT, Berkey CS, Coleman KA, Gardner J, Valadian I (1991) Long-term memory of body weight and past weight satisfaction: a longitudinal follow-up study. Am J Clin Nutr 53: 1493-1498

Chan JM, Stampfer MJ, Giovannucci E, Gann PH, Ma J, Wilkinson P, Hennekens CH, Pollak M (1998) Plasma insulin-like growth factor-I and prostate cancer risk: a prospective study. Science 279: 563-566

D’Avanzo B, La Vecchia C, Katsouyanni K, Negri E, Trichopoulos D (1997) An assessment, and reproducibility of food frequency data provided by hospital controls. Eur J Cancer Prev 6: $288-293$

Engeland A, Tretli S, Bjørge T (2003) Height, body mass index, and prostate cancer: a follow-up of 950000 Norwegian men. Br J Cancer 89: $1237-1242$

Freeman VL, Liao Y, Durazo-Arvizu R, Cooper RS (2001) Height and risk of fatal prostate cancer: findings from the national health interview survey (1986 to 1994). Ann Epidemiol 11: $22-27$

Giles GG, Severi G, English DR, McCredie MRE, MacInnis R, Boyle P, Hopper JL (2003) Early growth, adult body size and prostate cancer risk. Int J Cancer 103: $241-245$

Giovannucci E, Pollak M, Liu Y, Platz EA, Majeed N, Rimm EB, Willett WC (2003a) Nutritional predictors of insulin-like growth factor I and their relationships to cancer in men. Cancer Epidemiol Biomarkers Prev 12: $84-89$

Giovannucci E, Rimm EB, Liu Y, Leitzmann M, Wu K, Stampfer MJ, Willett WC (2003b) Body mass index and risk of prostate cancer in US health professionals. J Natl Cancer Inst 95: 1240 - 1244

Giovannucci E, Rimm EB, Stampfer MJ, Colditz GA, Willett WC (1997) Height, body weight, and risk of prostate cancer. Cancer Epidemiol Biomarkers Prev 6: $557-563$

Gleason DF, Mellinger GT (1974) The veterans administration cooperative urological research group: prediction of prognosis for prostatic adenocarcinoma by combined histological grading and clinical staging. J Urol 111: 58-64 ding measures even in older persons (Klipstein-Grobusch et al, 1998).

Hospital-based case-control studies may be more susceptible to selection and information bias than cohort studies (Breslow and Day, 1980). Cases and controls in our study, however, were selected from the same catchment's areas, and participation rate was equally high. Subjects with diseases potentially linked to diet and dietary modifications were excluded from the control group, and major confounding factors of prostate cancer were adjusted for. In particular, careful allowance was made for education and social class, which were directly related to prostate cancer risk, and may go along with a different prevalence of PSA testing.

In conclusion, this uniquely large case-control study on prostate cancer, conducted in a southern European population, showed no strong role for a wide range of anthropometric measures at various ages. However, weight gain early in adulthood seems to be a risk factor and supports a role for hormonal or metabolic correlates of overweight in the onset or progression of prostate cancers.

\section{ACKNOWLEDGEMENTS}

This work was conducted with the contribution of the Italian Association for Cancer Research and the Italian League Against Cancer, Milan. We thank Mrs Luigina Mei and Ilaria Calderan for editorial assistance.
Grönberg H (2003) Prostate cancer epidemiology. Lancet 361: 859-864 Gunnell D, Okasha M, Smith GD, Oliver SE, Sandhu J, Holly JM (2001) Height, leg length, and cancer risk: a systematic review. Epidemiol Rev 23: $313-342$

Habel LA, Van Den Eeden SK, Friedman GD (2000) Body size, age at shaving initiation, and prostate cancer in a large multiracial cohort. Prostate 43: $136-143$

Hsieh CC, Thanos A, Mitropoulos D, Deliveliotis C, Mantzoros CS, Trichopoulos D (1999) Risk factors for prostate cancer: a case-control study in Greece. Int J Cancer 80: 699-709

Hsing AW, Deng J, Sesterhenn IA, Mostofi FK, Stanczyk FZ, Benichou J, Xie T, Gao Y-T (2000) Body size and prostate cancer: a population-based case-control study in China. Cancer Epidemiol Biomarkers Prev 9: $1335-1341$

Hsing AW, Devesa SS (2001) Trends and patterns of prostate cancer: what do they suggest? Epidemiol Rev 23: 3-13

IARC Working Group on the Evaluation of Cancer-Preventive Strategies (2002) Weight control and physical activity. IARC Handbooks of Cancer Prevention 6, pp 117-120. Lyon: IARC Press

Klipstein-Grobusch K, Kroke K, Boeing H (1998) Reproducibility of selfreported past body weight. Eur J Clin Nutr 52: 525-528

Kolonel LN (1996) Nutrition and prostate cancer. Cancer Causes Control 7: $83-94$

MacInnis RJ, English DR, Gertig DM, Hopper JL, Giles GG (2003) Body size and composition and prostate cancer risk. Cancer Epidemiol Biomarkers Prev 12: $1417-1421$

Moyad MA (2002) Is obesity a risk factor for prostate cancer, and does it even matter? A hypothesis and different perspective.. Urology 59(Suppl $4 \mathrm{~A}): 41-50$

Nomura AM (2001) Body size and prostate cancer. Epidemiol Rev 23: $126-131$

Pollak M (2001) Insuline-like growth factors and prostate cancer. Epidemiol Rev 23: 59-66

Putnam SD, Cerhan JR, Parker AS, Bianchi GD, Wallace RB, Canctor KP, Lynch CF (2000) Lifestyle and anthropometric risk factors for prostate cancer in a cohort of Iowa men. Ann Epidemiol 10: 361-369

Rodriguez C, Patel AV, Calle EE, Jacobs EJ, Chao A, Thun MJ (2001) Body mass index, height, and prostate cancer mortality in two large cohorts of adult men in the United States. Cancer Epidemiol Biomarkers Prev 10: $345-353$ 
Signorello LB, Adami H-O (2002) Prostate cancer. In Textbook of Cancer Epidemiology, Adami H-O, Hunter D, Trichopoulos D (eds). pp 400-428. New York: Oxford University Press

Sobin LH, Wittekind CH (eds) (1997) TNM Classification of Malignant Tumours, 5th edn, New York: Wiley-Liss

Villeneuve PJ, Johnson KC, Kreiger N, Mao Y, The Canadian Cancer Registries Epidemiology Research Group (1999) Risk factors for prostate cancer: results from Canadian national enhanced cancer surveillance system. Cancer Causes Control 10: 355-367
Whittemore AS, Kolonel LN, Wu AH, John EM, Gallagher RP, Howe GR, Burch JD, Hankin J, Dreon DM, West DW, The C-Z, Paffenbarger Jr RS (1995) Prostate cancer in relation to diet, physical activity, and body size in blacks, whites, and Asians in the United States and Canada. J Natl Cancer Inst 87: $652-661$

Willett W (1999) Anthropometric measures and body composition. In Nutritional Epidemiology, Willett W (ed) pp 217-244. New York: Oxford University Press 